\title{
ERPs TO NOUNS AND VERBS - CONGRUENCES AND DIFFERENCES
}

\author{
Josef Petřek \\ Institute of Physiology, Faculty of Medicine, Palacký University, 77515 Olomouc, Czech Republic \\ e-mail:fesoj@tunw.upol.cz
}

Received: July 10, 2004, Accepted: September 4, 2004

Key words: ERPs/Nouns/Verbs/Gender/Site of recording electrode

The results of the multivariate analysis of variance confirmed statistically significant differences in latency and amplitude of some ERPs waves to nouns and ERPs to verbs. ERPs to nouns differ from ERPs to verbs by a significantly longer latency and greater amplitude of some waves. A comparison of the characteristics of ERPs to nouns and ERPs to verbs separately in males and females produced basically identical results; in females, however, there are much fewer significant differences than in males. Interaction between the site of the recording electrode and features of ERPs to words of different word classes however could not be demonstrated.

\section{INTRODUCTION}

Clinical observations in aphatics show that lesions in a particular cortical area do not affect to the same degree language processing of nouns and verbs. Goodglas et al. ${ }^{7}$ demonstrated that patients with Broca's aphasia have a deficit in the ability to name activities whereas patients with fluent aphasia make more errors in the naming of objects. Miceli et al. ${ }^{9}$ established the existence of patients with selective, or relatively selective, disorders in naming and comprehension of nouns and verbs; lesion in the cortex of the left temporal lobe was often accompanied by selective disorders in the processing of nouns, while lesion in the cortex of the left prefrontal area brought deficits in verb processing. This is supported by the findings of Damasio and Tranel ${ }^{4}$ and Daniele et al. ${ }^{5}$. They too confirmed the existence of a correlation between the area of cortical lesion and the type of disorder in processing verbs and nouns; in the report by Damasio and Tranel the location of the lesion was carefully assessed with magnetic resonance imaging.

In this context it should be said, however, that in the literature, data could be found which do not fit the above correlation. Thus e.g. De Renzi and Di Pellegrino ${ }^{6}$ reported a patient with lesion of temporal lobe who had sparing of action naming and verb generation. Silveri and Di Betta ${ }^{18}$ also report patients with a selective disorder of distinguishing between nouns and verbs. The patient with a lesion in the left temporal and parietal lobes had no problems in the use of verbs and but did not have full command of nouns, even though he understood their meanings. On the other hand, another patient with the same localised lesion had problems with the production of verbs - he could not pronounce them.

The fact that distinct neural systems participate in the language processing of nouns and verbs has been confirmed by electrophysiological studies, too - see e.g. ${ }^{1,2,3,8,10,12,14-17,19}$, etc. This presentation extends the se-

Table 1. Multivariate analysis of variance: ERPs data

\begin{tabular}{|l|c|c|c|c|c|c|}
\hline & \multicolumn{6}{|c|}{ Table of all effects: ERPs data } \\
\hline Effect & Test & Value & F & Effect df & Error df & $\mathrm{p}$ \\
\hline Gender & Wilks & 0.611808 & 32.96 & 18 & 935.000 & 0.000000 \\
\hline Electrode & Wilks & 0.272277 & 12.66 & 108 & 5365.719 & 0.000000 \\
\hline Gender $\times$ Word class & Wilks & 0.943300 & 3.12 & 18 & 935.000 & 0.000013 \\
\hline Gender $\times$ Electrode & Wilks & 0.788261 & 2.11 & 108 & 5365.719 & 0.000000 \\
\hline Word class $\times$ Electrode & Wilks & 0.955319 & 0.40 & 108 & 5365.719 & 1.000000 \\
\hline Gender $\times$ Word class $\times$ Electrode & Wilks & 0.951009 & 0.44 & 108 & 5365.719 & 1.000000 \\
\hline
\end{tabular}


ries of studies dealing with electrophysiological aspects of language processing of nouns and verbs in the brain.

\section{METHODS}

The experimental paradigm, features of word stimuli and methods of data acquisition and analysis are described in detail in a preceding paper ${ }^{11}$.

\section{RESULTS}

\section{Word classes and features of ERPS}

The results of a multivariate analysis of variance (Table 1) reveal a statistically significant difference in latency and amplitude of each component of ERPs to nouns and ERPs to verbs; for a specification of individual ERP components see Petrek ${ }^{11}$. In addition to the verbal stimulus the gender of the participants and the site of the recording electrode on the scalp affect the parameters of ERP.

ERPs to nouns differ from ERPs to verbs by a significantly longer latency of LP2 wave and greater amplitude of waves BP3 and BN4. A higher value in ERPs to nouns is also found in the parameter PV2. Different, however, is the behaviour of the amplitude of waves BN1 and BN3 - their amplitudes in ERPs to nouns are smaller (see the first two lines in Table 2).

A comparison of the features of ERPs to nouns and ERPs to verbs, separately in males and females, brings basically the same results (see Table 2, lines 3 to 6). Nevertheless, there is one substantial difference: there are far fewer significant differences between ERPs to nouns and ERPs to verbs in females than in males.

The interaction between the word classes and gender is made clearer by a comparison of latencies and amplitudes of ERPs to nouns or ERPs to verb in males and females (see the last four lines in Table 2). Briefly: If latency differences are significant, then in females latency of waves LP2, LN1 and LN4 (with the exception of wave LN2) is significantly shorter than in males, and this is so regardless which of the two stimuli (nouns or verbs) produced it. The amplitude of six components of ERPs (BP1, BP2, $\mathrm{BN} 2, \mathrm{BN} 4, \mathrm{PV} 1, \mathrm{PV} 2$ ) is higher in females than in males, the amplitude of two (BP4 and BN1) is lower.

\section{ERPs to nouns/verbs and the site of electrodes}

Statistical analysis of data obtained in our experiment (see Table 1) failed to demonstrate any interaction between the site of the recording electrode and characteristics of ERPs to words of different word classes. The differences observed in latency and amplitude of each wave of ERPs to nouns and ERPs to verbs are statistically insignificant.

It was revealed, however, that there are statistically significant differences in amplitude (latency differences are statistically insignificant) of some waves of ERPs recorded by electrodes at anterior and posterior sites, and this is so regardless of to which word class ERPs producing the stimulus belongs.

The amplitude of each component of ERPs increases in anterior-posterior dimensions. Thus the smallest amplitude is in electrodes at sites F3/F4, medium at sites C3/C4 and maximal at sites P3/P4 (see Table 3). It should

Table 2. Basic features of ERPs to verbs (V) and nouns (S) in males (1) and females (2)

\begin{tabular}{|c|c|c|c|c|c|c|c|c|c|c|c|c|c|c|c|c|c|c|c|c|}
\hline \multirow{2}{*}{$\begin{array}{l}\dot{0} \\
\overline{0} \\
0\end{array}$} & \multirow{2}{*}{$\begin{array}{l}n \\
\vdots \\
3\end{array}$} & \multirow[t]{2}{*}{$\mathrm{N}$} & $\mathrm{L}$ & A & $\mathrm{L}$ & A & $\mathrm{L}$ & A & $\mathrm{L}$ & A & $\mathrm{L}$ & A & $\mathrm{L}$ & A & $\mathrm{L}$ & A & $\mathrm{L}$ & A & A & A \\
\hline & & & LP1 & BP1 & LP2 & BP2 & LP3 & BP3 & LP4 & BP4 & LN1 & BN1 & LN2 & BN2 & LN3 & BN3 & LN4 & BN4 & PV1 & PV2 \\
\hline & $\mathrm{V}$ & 360 & 132.5 & 168.8 & 229.4 & 172.6 & 482.2 & 157.5 & 582.0 & 158.3 & 179.2 & 162.7 & 283.1 & 126.3 & 398.4 & 223.8 & 732.5 & 140.4 & 435.1 & 334.7 \\
\hline & $\mathrm{S}$ & 480 & 131.2 & 181.8 & 233.3 & 181.1 & 484.9 & 186.6 & 583.3 & 157.4 & 180.9 & 136.8 & 283.5 & 114.1 & 398.9 & 193.2 & 735.5 & 161.3 & 411.6 & 385 \\
\hline
\end{tabular}

\begin{tabular}{|l|l|l|l|l|l|l|l|l|l|l|l|l|l|l|l|l|l|l|l|l|l|}
\hline 1 & $\mathrm{~V}$ & 126 & 134.1 & $\mathbf{1 5 4 . 8}$ & $\mathbf{2 3 4 . 6}$ & 123.6 & 479.4 & $\mathbf{1 6 7 . 1}$ & 581.7 & 181.2 & 184.1 & $\mathbf{1 8 8 . 9}$ & 276.5 & 111.1 & 400.3 & $\mathbf{2 2 1 . 8}$ & 751.1 & 116.8 & 398.2 & $\mathbf{2 9 4 . 5}$ \\
1 & $\mathrm{~S}$ & 168 & 129.4 & $\mathbf{1 8 7 . 3}$ & $\mathbf{2 4 0 . 6}$ & 141.6 & 484.0 & $\mathbf{2 0 1 . 1}$ & 582.1 & 195.5 & 186.6 & $\mathbf{1 5 9 . 7}$ & 271.0 & 101.3 & 395.3 & $\mathbf{1 8 3 . 2}$ & 754.8 & 141.4 & 369.8 & $\mathbf{3 7 9 . 5}$ \\
\hline 2 & $\mathrm{~V}$ & 234 & 131.0 & 182.8 & 224.3 & 221.5 & 485.1 & 147.9 & 582.3 & 135.3 & 174.4 & $\mathbf{1 3 6 . 5}$ & 289.7 & 141.5 & 396.4 & $\mathbf{2 2 5 . 9}$ & 714.0 & 163.9 & 471.9 & 374.9 \\
2 & $\mathrm{~S}$ & 312 & 133.0 & 176.3 & 226.1 & 220.6 & 485.8 & 172.1 & 584.4 & 119.2 & 175.3 & $\mathbf{1 1 3 . 9}$ & 296.0 & 126.9 & 402.5 & $\mathbf{2 0 3 . 1}$ & 716.1 & 181.3 & 453.4 & 391.2 \\
\hline
\end{tabular}

\begin{tabular}{|l|l|l|l|l|l|l|l|l|l|l|l|l|l|l|l|l|l|l|l|l|l|}
\hline 1 & $\mathrm{~V}$ & 126 & 134.1 & $\mathbf{1 5 4 . 8}$ & $\mathbf{2 3 4 . 6}$ & $\mathbf{1 2 3 . 6}$ & 479.4 & 167.1 & 581.7 & $\mathbf{1 8 1 . 2}$ & $\mathbf{1 8 4 . 1}$ & $\mathbf{1 8 8 . 9}$ & $\mathbf{2 7 6 . 5}$ & $\mathbf{1 1 1 . 1}$ & 400.3 & 221.8 & $\mathbf{7 5 1 . 1}$ & $\mathbf{1 1 6 . 8}$ & $\mathbf{3 9 8 . 2}$ & $\mathbf{2 9 4 . 5}$ \\
2 & $\mathrm{~V}$ & 234 & 131.0 & $\mathbf{1 8 2 . 8}$ & $\mathbf{2 2 4 . 3}$ & $\mathbf{2 2 1 . 5}$ & 485.1 & 147.9 & 582.3 & $\mathbf{1 3 5 . 3}$ & $\mathbf{1 7 4 . 4}$ & $\mathbf{1 3 6 . 5}$ & $\mathbf{2 8 9 . 7}$ & $\mathbf{1 4 1 . 5}$ & 396.4 & 225.9 & $\mathbf{7 1 4 . 0}$ & $\mathbf{1 6 3 . 9}$ & $\mathbf{4 7 1 . 9}$ & $\mathbf{3 7 4 . 9}$ \\
\hline 1 & $\mathrm{~S}$ & 168 & 129.4 & 187.3 & $\mathbf{2 4 0 . 6}$ & $\mathbf{1 4 1 . 6}$ & 484.0 & $\mathbf{2 0 1 . 1}$ & 582.1 & $\mathbf{1 9 5 . 5}$ & $\mathbf{1 8 6 . 6}$ & $\mathbf{1 5 9 . 7}$ & $\mathbf{2 7 1 . 0}$ & $\mathbf{1 0 1 . 3}$ & 395.3 & 183.2 & $\mathbf{7 5 4 . 8}$ & $\mathbf{1 4 1 . 4}$ & $\mathbf{3 6 9 . 8}$ & 379.5 \\
2 & $\mathrm{~S}$ & 312 & 133.0 & 176.3 & $\mathbf{2 2 6 . 1}$ & $\mathbf{2 2 0 . 6}$ & 485.8 & $\mathbf{1 7 2 . 1}$ & 584.4 & $\mathbf{1 1 9 . 2}$ & $\mathbf{1 7 5 . 3}$ & $\mathbf{1 1 3 . 9}$ & $\mathbf{2 9 6 . 0}$ & $\mathbf{1 2 6 . 9}$ & 402.5 & 203.1 & $\mathbf{7 1 6 . 1}$ & $\mathbf{1 8 1 . 3}$ & $\mathbf{4 5 3 . 4}$ & 391.2 \\
\hline
\end{tabular}

$\mathrm{N}$ - number of measurements in the set.

L - latencies (in ms) of positive (LP1, LP2, LP3, LP4) and negative (LN1, LN2, LN3, LN4) waves of ERPs.

A - amplitudes (in mV) of positive (BP1, BP2, BP3, BP4) and negative (BN1, BN2, BN3, BN4) waves of ERPs.

PV1 - voltage between peaks P1/P2 and valley N3, PV2 - voltage between peaks P3/P4 and valley N4; Amplitude calibration: $1 \mu \mathrm{V}=40 \mathrm{mV}$.

Bold numbers on a gray background - the difference between two means is significant at the $5 \%$ level. 
Table 3. Comparison of amplitudes of ERPs to verbs (V) and nouns (S) over the left (F3, C3, P3) and right (F4, C4, P4) hemisphere

\begin{tabular}{|c|c|c|r|r|r|r|r|r|r|r|r|r|}
\hline $\begin{array}{c}\text { Elec- } \\
\text { trode }\end{array}$ & Words & N & $\begin{array}{c}\text { A } \\
\text { BP1 }\end{array}$ & $\begin{array}{c}\text { A } \\
\text { BP2 }\end{array}$ & $\begin{array}{c}\text { A } \\
\text { BP3 }\end{array}$ & $\begin{array}{c}\text { A } \\
\text { BP4 }\end{array}$ & $\begin{array}{r}\text { A } \\
\text { BN1 }\end{array}$ & $\begin{array}{c}\text { A } \\
\text { BN2 }\end{array}$ & $\begin{array}{c}\text { A } \\
\text { BN3 }\end{array}$ & $\begin{array}{c}\text { A } \\
\text { BN4 }\end{array}$ & $\begin{array}{c}\text { A } \\
\text { PV1 }\end{array}$ & $\begin{array}{c}\text { A } \\
\text { PV2 }\end{array}$ \\
\hline F3 & V & 60 & $\mathbf{8 2 . 4}$ & $\mathbf{9 5 . 9}$ & 139.8 & 113.8 & $\mathbf{8 0 . 8}$ & 121.4 & $\mathbf{7 9 . 6}$ & 121.7 & $\mathbf{1 9 3 . 0}$ & 279.5 \\
C3 & V & 60 & $\mathbf{1 6 5 . 9}$ & $\mathbf{1 7 4 . 1}$ & 207.0 & 185.5 & $\mathbf{1 1 3 . 2}$ & 180.2 & $\mathbf{1 9 7 . 6}$ & 181.1 & $\mathbf{4 4 4 . 4}$ & 405.8 \\
P3 & V & 60 & $\mathbf{1 9 7 . 2}$ & $\mathbf{2 2 3 . 6}$ & 134.9 & 150.3 & $\mathbf{2 8 3 . 0}$ & 107.9 & $\mathbf{2 8 7 . 5}$ & 136.3 & $\mathbf{5 3 2 . 7}$ & 313.9 \\
\hline F3 & S & 80 & $\mathbf{8 2 . 2}$ & $\mathbf{1 0 2 . 9}$ & 151.0 & 118.3 & $\mathbf{5 7 . 8}$ & 105.4 & $\mathbf{5 7 . 7}$ & 118.3 & $\mathbf{1 7 5 . 2}$ & 289.1 \\
C3 & S & 80 & $\mathbf{1 9 2 . 3}$ & $\mathbf{2 0 0 . 7}$ & 250.9 & 185.0 & $\mathbf{8 4 . 5}$ & 153.0 & $\mathbf{1 6 3 . 9}$ & 206.4 & $\mathbf{4 2 7 . 2}$ & 489.3 \\
P3 & S & 80 & $\mathbf{2 2 1 . 7}$ & $\mathbf{2 4 3 . 6}$ & 168.3 & 155.9 & $\mathbf{2 4 4 . 9}$ & 98.3 & $\mathbf{2 4 5 . 7}$ & 167.0 & $\mathbf{5 1 6 . 0}$ & 375.3 \\
\hline
\end{tabular}

Grey columns - mean amplitudes of ERPs components showing significant differences in an anterior-posterior direction over hemispheres. For the others see the text to Table 2.

be added that differences in amplitude of each component of ERPs triggered by nouns or verbs in symmetrical electrodes in the left and right hemispheres are in most cases insignificant. The only exception is amplitude BN3, which in electrodes over the right hemisphere is greater than in electrodes over the left hemisphere.

\section{DISCUSSION}

The fact that various functional systems cooperate in language processing of nouns and verbs has been confirmed by electrophysiological studies (see e.g. 1,8,10,12, 14-16,19, etc.). Teyler et al. ${ }^{19}$ found that nouns and verbs presented by sound evoke clear N100-P160 in both hemispheres, the latencies of which on the left hemisphere are shorter to verb stimuli than to noun stimuli. The presented results also show that verbs trigger ERPs with shorter latency than do nouns. However, contrary to Teyler, we did not find hemispheric differences in latencies of ERPs to verbs.

The results of the present study are in some ways in conflict with those of Pulvermüller et al. ${ }^{12-17}$. The authors quoted above showed that action verbs evoke high amplitude ERPs in frontal and central areas of both hemispheres, nouns in occipital areas, verbs with relation to activity of lower limbs at vertex, i.e. about the motor cortical representation of the leg, and the like. An analysis of ERPs registered in our subjects failed to confirm that relation. It emerged, however, that in hemispheres the amplitude of ERPs waves grows in the anterior-posterior direction, i.e. it is smallest in electrodes F3, F4 and largest in electrodes P3, P4, regardless of which word class evoked the ERPs.

The comparison of our findings with those of other authors must end with the statement that so far we have been unable to specify unambiguously the cause of the differences observed. Very likely a role is played by the real experimental paradigm, the technique of data registration, stimulus parameters, number and location of the recording electrodes on the scalp, and last but not least, the method of signal analysis. Thus it is obvious that only many better planned and performed experiments can reveal the true causes of the differences between the findings of other authors and us.

\section{REFERENCES}

1. Brown WS, Marsh JT, Smith JC. (1973) Contextual meaning effects on speech evoked potentials. Behav Biol 9, 755-761.

2. Brown WS, Marsch JT, Smith JC. (1976) Evoked potential waveform differences produced by the perception of different meanings of an ambiguous phrase. Electroencephalog Clin Neurophysiol 41, $113-123$.

3. Brown WS, Marsch JT, Smith JC. (1979) Principal component analysis of ERP differences related to the meaning of an ambiguous word. Electroencephalog Clin Neurophysiol 46, 709-714.

4. Damasio AR, Tranel D. (1993) Nouns and verbs are retrieved with differently distributed neural systems. Proc Natl Acad Sci USA 90, 4957-4960.

5. Daniele A, Giustolisi L, Silveri CM, Colosimo C, Gainotti G. (1994) Evidence for a possible neuroanatomical basis for the lexical processing of nouns and verbs. Neuropsychologia 32, 13251342.

6. De Renzi E, Di Pellegrino G. (1995) Sparing of verbs and preserved, but ineffectual reading in a patient with impaired word production. Cortex 31, 619-636.

7. Goodglass H, Klein B, Carey P, Jones K. (1966) Specific semantic word category in aphasia. Cortex 2, 74-89.

8. Koenig T, Lehmann D. (1996) Microstates in language-related brain potential maps show noun-verb differences. Brain Lang 53, 169-182.

9. Miceli G, Silveri MC, Nocentini U, Caramazza A. (1988) Patterns of dissociation in comprehension and production of nouns and verbs. Aphasiology 2, 251-258. 
10. Molfese DL, Burger-Judisch LM, Gill LA, Golinkoff RM, HirschPasek KA. (1996) Electrophysiological correlates of noun-verb processing in adults. Brain Lang 54, 388-413.

11. Petřek J. (2004) ERPs to words - Effect of gender and site of registration electrode. Biomed. Papers 148, 145-152.

12. Pulvermüller F, Preissl H, Lutzenberger W, Birbaumer N. (1996) Brain rhythms of language: nouns versus verbs. Europ J Neurosci 8, 937-941.

13. Pulvermüller F. (1999) Words in the brain's language. Behav Brain Sci 22, 253-336.

14. Pulvermüller F, Lutzenberger W, Preissl H. (1999a) Nouns and verbs in the intact brain: Evidence from event-related potentials and high-frequency cortical responses. Cerebral Cortex 9, 497-506.
15. Pulvermüller F, Mohr B, Schleichert H. (1999b) Semantic or lexicosyntactic factors: what determines word-class specific activity in the human brain? Neurosci Lett 275, 81-84.

16. Pulvermüller F, Härle M, Hummel F. (2000) Neurophysiological distinction of verb categories. Neuroreport 11, 2789-2793.

17. Pulvermüller F, Härle M, Hummel F. (2001) Walking or Talking?: Behavioral and neurophysiological correlates of action verb processing. Brain Lang 78, 143-168.

18. Silveri M, Di Betta AM. (1997) Noun-verb dissociation in braindamaged patients: Further evidence. Neurocase 3, 477-488.

19. Teyler T, Roemer RR, Harrison T, Thompson R. (1973) Human scalprecorded evoked potential correlates of linguistic stimuli. Bull Psychonom Soc 1, 333-334. 